\title{
Fatal complications associated with surgical left atrial appendage exclusion
}

\author{
Mahmoud Sleiman Wehbe, MD, Nicolas Doll, MD, PhD, and Denis Rouven Merk, MD, Stuttgart, Germany
}

\author{
From the Department of Cardiac Surgery, Sana Heart Surgery Stuttgart, Stuttgart, Germany. \\ Disclosures: Authors have nothing to disclose with regard to commercial support. \\ Received for publication March 24, 2018; revisions received May 9, 2018; accepted for publication May 16, 2018; \\ available ahead of print June 28, 2018. \\ Address for reprints: Mahmoud Sleiman Wehbe, MD, Department of Cardiac Surgery, Sana Herzchirurgie Stutt- \\ gart, Herdweg 2, Stuttgart 70174, Germany (E-mail: mahmoud.wehbe@sana.de). \\ J Thorac Cardiovasc Surg 2018;156:e207-8 \\ $0022-5223 / \$ 36.00$ \\ Copyright (c) 2018 by The American Association for Thoracic Surgery \\ https://doi.org/10.1016/j.jtcvs.2018.05.066
}

The left atrial appendage (LAA) is a common source of cardiogenic emboli resulting in stroke. LAA exclusion during surgical ablation of atrial fibrillation (AF) to reduce stroke risk has gained popularity, and complications are rare. We report the cases of patients with $\mathrm{AF}$ and dilated left atria who underwent concomitant LAA exclusion, with resultant myocardial tearing at the site of exclusion.

\section{CLINICAL SUMMARY}

\section{Case 1}

A 67-year-old female patient with morbid obesity $\left(41.2 \mathrm{~kg} / \mathrm{m}^{2}\right)$ had an 8-year history of long standing persistent $\mathrm{AF}$, presenting with dyspnea, palpitations, and dizziness, so that normal daily activities were discontinued. She underwent totally thoracoscopic maze ablation with staple exclusion (Endo-GIA; Medtronic, Minneapolis, Minn) of the LAA, as previously described. ${ }^{1}$ Preoperative transesophageal echocardiography revealed mild mitral regurgitation and a left atrial diameter measuring $60 \mathrm{~mm}$. The left ventricular ejection fraction (LVEF) was $43 \%$. After consultations with the rhythmology department, success with catheter-based pulmonary vein isolation was considered less likely because of the left atrial dimensions.

After an uneventful intra-operative course, the patient was discharged in sinus rhythm to the cardiosurgical intensive care unit. During ventilation weaning, a coughing episode preceded sudden acute blood loss, with rapid filling of both left- and right-sided pleural drains and circulatory compromise, warranting emergency thoracotomy and cardiopulmonary bypass support. Transesophageal echocardiography identified a large pericardial effusion with substantial air artifacts in the left ventricle (Figure 1, A). A tear at the base of the excluded LAA near the mitral valve annulus could be identified and was managed with composite felt pledgeted sutures. Neurologic deficit the next morning prompted cranial computed tomographic imaging, which confirmed a stroke involving the majority of the right

\section{Case 2} postoperative day.

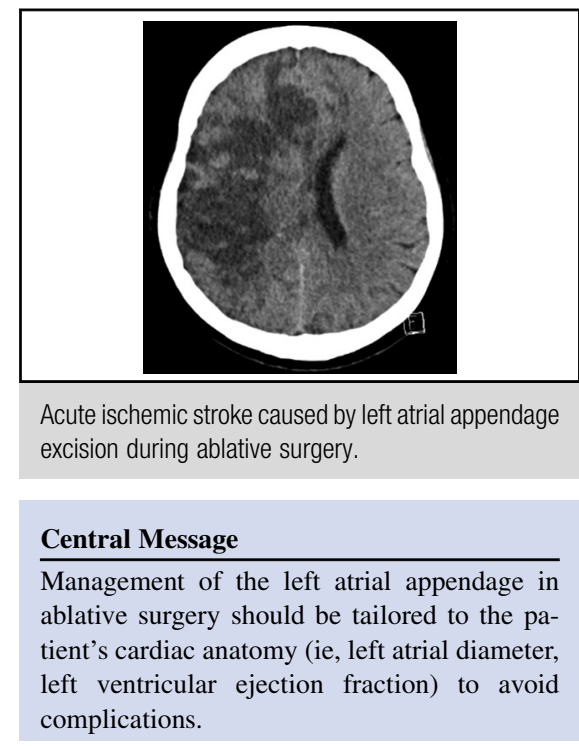

See Editorial Commentary page e209.

cerebral hemisphere (Figure 1, $B$ ). The patient was referred to neurosurgery for emergency craniotomy and died 4 weeks later as result of extensive neurological insult.

A 79-year-old male patient with permanent AF for 9 years and severe mitral regurgitation who had undergone mitral clipping 2 weeks earlier was referred to our clinic for mitral valve repair with LAA exclusion. Transthoracic echocardiography revealed a left atrium measuring $63 \mathrm{~mm}$ and grade 4 mitral regurgitation. The LVEF was $32 \%$.

After a right-sided minithoracotomy and cardiopulmonary bypass cannulation of the right femoral vessels, an atrial septal defected was directly sutured, and the LAA was managed by endocardial double running suture closure. The mitral valve was replaced because of extensive damage to both mitral valve leaflets from the clipping device. After cardiopulmonary bypass termination, sudden hemodynamic comprise with evidence of a pericardial effusion in transesophageal echocardiography warranted emergency median sternotomy. A tear between the mitral valve annulus and the base of the LAA was managed with felt pledgeted sutures and an autologous pericardial patch to close the defect. The patient died of low cardiac output on the second 

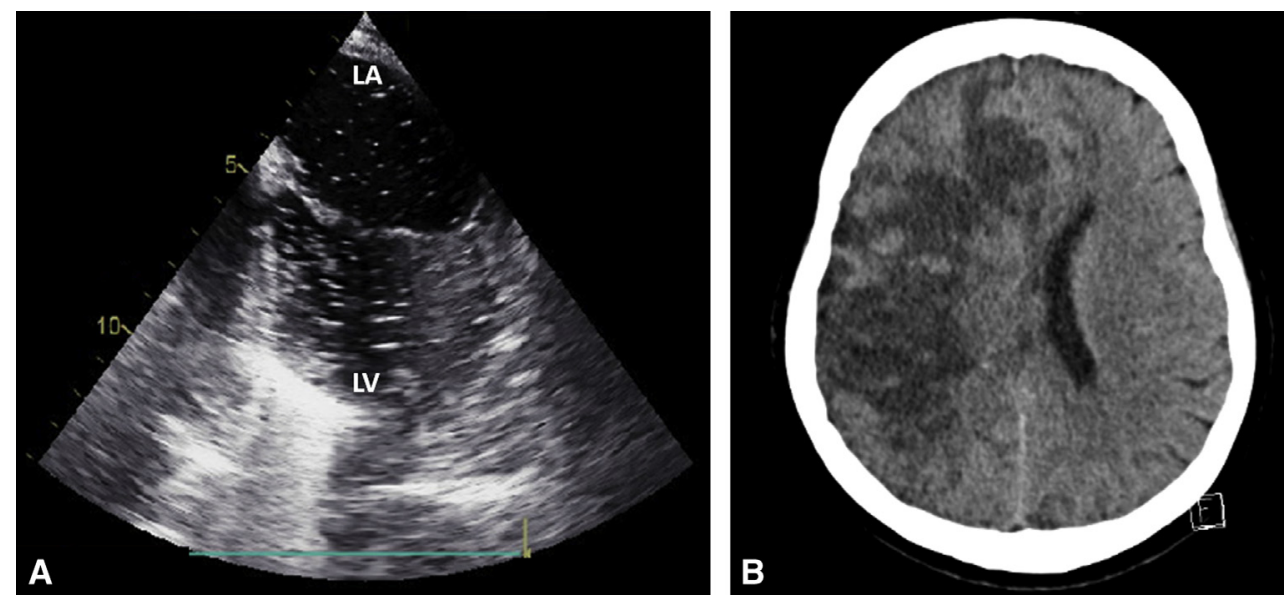

FIGURE 1. A, On transesophageal echocardiography, substantial air artifacts were visible in the left atrium $(L A)$ and the left ventricle ( $L V)$. B, These air artifacts resulted in a dramatic fatal ischemic stroke, with tentorial shifting and obliteration of the right lateral ventricle, as seen on cranial computed tomography.

\section{DISCUSSION}

The LAA, infamously labeled "our most lethal attachment" ${ }^{\prime 2}$ because of its inherent anatomy and the pathophysiologic mechanisms associated with AF (hypercoagulability, endothelial damage), is the main source of cardiogenic emboli, accounting for $57 \%$ and $91 \%$ of thrombi in valvular and nonvalvular $\mathrm{AF}$, respectively. ${ }^{3} \mathrm{In}$ a retrospective cohort detailing more than 10,000 patients, concomitant surgical LAA occlusion was associated with lower risk of thromboembolism at 3-years follow-up. ${ }^{4}$

LAA exclusion during ablative procedures in cardiac surgery has become routine practice. Surgical exclusion strategies to exclude the LAA can be achieved endocardially or epicardially, with or without device assistance. Acute complications, such as tearing, are rare. The method of LAA exclusion is usually dictated by the concomitant cardiosurgical procedure. At our establishment, a surgical stapler (Endo-GIA) is routinely applied to amputate the LAA during totally thoracoscopic maze procedures. Our experience has been reported, and results are favorable. ${ }^{1}$

The patients had a long history of AF, severely dilated left atrium, and reduced LVEF. In case 1, compression of left atrial tissue by the stapler device and the mechanical stress applied to the staple line from the dynamic process of the cardiac cycle may have promoted tearing. This stapling device was sent to the manufacturer, and device malfunction was excluded. In the second case, repetitive trauma induced by suturing of the mitral valve prothesis and LAA suture ligation may have further weakened the structural integrity of the diseased left atrium. In both patients, tearing occurred at the inferior aspect of the LAA, near its junction with the mitral valve annulus.

The LAA of a chronically fibrillating dilated left atrium larger than $60 \mathrm{~mm}$ should be manipulated delicately, and trauma should be minimized. Deployment of a novel LAA clip exclusion system at the base of the LAA is atraumatic, and the structural integrity of left atrial myocardium is maintained. A prospective register has reported a $100 \%$ LAA occlusion rate with this device and confirmed its safety profile.

Caution should be exercised in treating the LAA of patients with a reduced LVEF and severely dilated left atria related to long-standing atrial fibrillation. Occlusion by means of an atraumatic exclusion device should be considered for its potential to minimize complications.

\section{References}

1. Weimar T, Vosseler M, Czesla M, Boscheinen M, Hemmer WB, Doll KN. Approaching a paradigm shift: endoscopic ablation of lone atrial fibrillation on the beating heart. Ann Thorac Surg. 2012;94:1886-92.

2. Johnson WD, Ganjoo AK, Stone CD, Srivyas RC, Howard M. The left atrial appendage: our most lethal human attachment! Surgical implications. Eur J Cardiothorac Surg. 2000;17:718-22.

3. Blackshear JL, Odell JA. Appendage obliteration to reduce stroke in cardiac surgical patients with atrial fibrillation. Ann Thorac Surg. 1996;61:755-9.

4. Friedman DJ, Piccini JP, Wang T, Zheng J, Malaisrie SC, Holmes DR, et al. Association between left atrial appendage occlusion and readmission for thromboembolism among patients with atrial fibrillation undergoing concomitant cardiac surgery. JAMA. 2018;319:365-74.

5. Caliskan E, Sahin A, Yilmaz M, Seifert B, Hinzpeter R, Alkadhi H, et al. Epicardial left atrial appendage AtriClip occlusion reduces the incidence of stroke in patients with atrial fibrillation undergoing cardiac surgery. Europace. July 18, 2017 [Epub ahead of print]. 